\title{
PROJETO VICTOR: PERSPECTIVAS DE APLICAÇÃO DA INTELIGÊNCIA ARTIFICIAL AO DIREITO
}

\author{
VICTOR PROJECT: PERSPECTIVES OF APPLYING ARTIFICIAL \\ INTELLIGENCE TO THE LAW
}

Mamede Said Maia Filho

Tainá Aguiar Junquilho

\section{RESUMO}

Este artigo analisa o potencial que a inteligência artificial (IA) tem para impactar o Direito, discutindo como as ferramentas tecnológico-algorítmicas podem contribuir para diminuição da elevada taxa de congestionamento do Poder Judiciário brasileiro. Examinando as inovações que a IA permite, apresenta o Projeto Victor, fruto de parceria do Supremo Tribunal Federal com a Universidade de Brasília, que prevê a criação de modelos de machine learning para análise dos recursos recebidos pelo STF quanto aos temas de repercussão geral. Como se buscou comprovar, o projeto poderá se constituir em ferramenta que afetará positivamente o controle de constitucionalidade difuso realizado pela Corte.

Palavras-chave: Direito e tecnologia. Inteligência Artificial. Projeto Victor.

\section{ABSTRACT}

This article analyzes the potential that artificial intelligence (AI) has to impact the Law, discussing how the technological-algorithmic tools can contribute to decrease the high congestion rate of the Brazilian Judiciary. Examining the innovations that AI allows, it presents the Victor Project, the result of a partnership between the Supreme Court and the University of Brasilia, which foresees the creation of machine learning models for the analysis of 
the extraordinary appeas received by the Supreme Court on issues of general repercussion. As it is expected to be proved, the project could constitute a tool that will positively affect the diffuse constitutionality control carried out by the Court.

Keywords: Law and technology. Artificial intelligence. Victor Project.

\section{INTRODUÇÃo}

Em Admirável Mundo Novo, romance no qual Aldous Huxley, há quase 90 anos, antecipou a adoção, em uma fictícia sociedade futurista, de muitos avanços tecnológicos que vieram depois a se tornar realidade ${ }^{1}$, o personagem Mustafá Mond diz que "qualquer mudança é uma ameaça para a estabilidade", sendo essa uma das razões pela qual somos pouco propensos a aplicar novas invenções. Toda descoberta da ciência pura é potencialmente subversiva, diz o personagem, o que levaria a considerar que "por vezes, até mesmo a ciência deve ser tratada como um inimigo possível” (HUXLEY, 1969, p. 277-278). As inovações que a aplicação de inteligência artificial (IA) hoje permite têm o mesmo potencial disruptivo que os cenários da sociedade pensada por Huxley apresentam, e até mesmo o temor dos perigos que os avanços da IA podem gerar coincidem com os receios que o universo fictício de Admirável Mundo Novo traz à tona ${ }^{2}$.

Aplicada nos mais diferentes setores da atividade humana ${ }^{3}$, a IA tem potencial para promover radicais impactos no congestionado e moroso sistema judicial brasileiro. Embora já seja utilizada na prestação de serviços jurídicos na esfera privada, ela ainda não foi suficientemente reconhecida como essencial para que o Poder Judiciário, frente aos elevados dados de litigiosidade existentes, possa oferecer maior eficiência e qualidade nos serviços que lhe incumbe prestar em nome do Estado brasileiro.

O processo de redemocratização vivenciado a partir de 1985 e a promulgação da Constituição de 1988 tiveram um impacto positivo no sentido de estimular os indivíduos e os grupos sociais a reivindicar seus direitos e garantias. Entretanto, por ser uma Constituição analítica e prolixa, que trata de matérias relacionadas a praticamente todas as áreas 
jurídicas, a Carta de 1988 acabou por gerar uma excessiva judicialização das relações sociais. Como assinala Luís Roberto Barroso, (2008), a consequência é que os órgãos do Poder Judiciário, aí incluído o Supremo Tribunal Federal, foram chamados a dar a última palavra em temas os mais variados, que envolvem direitos fundamentais, políticas públicas, regimes jurídicos dos servidores, sistema político e inúmeras outras questões de menor destaque. Essa expansão do papel do Judiciário, notadamente do STF, teve como consequência o aumento exponencial do volume de processos entrantes no sistema judicial.

Dados do Relatório Justiça em Números 2017, editado pelo Conselho Nacional de Justiça (CNJ), deixam claro que a taxa de congestionamento do Poder Judiciário, que mede o percentual de processos que ficam represados sem solução ao final de cada ano, segue em patamares insustentáveis. 0 número de processos cresceu de forma significativa desde 2009, ano inicial da série histórica analisada pelo CNJ, como também os recursos internos e os incidentes julgados e em trâmite. Assim, o Poder Judiciário finalizou o ano de 2016 com 79,7 milhões de processos em tramitação. Durante esse ano, embora tenham sido baixados 29,4 milhões de processos, houve o mesmo quantitativo ingressado, 29,4 milhões (CNJ, 2017, p. 67). Tal situação impõe a necessidade de se buscar alternativas que permitam que o volume de processos e o modelo de legislação processual existente não tornem cada vez mais tardia, senão inviabilizem de modo comprometedor, a prestação jurisdicional.

A situação de morosidade e o congestionamento que caracteriza a estrutura judicial geram um inevitável aumento de seus custos. Em 2016, as despesas totais do Poder Judiciário corresponderam a 1,4\% do Produto Interno Bruto (PIB) nacional, ou a 2,5\% dos gastos da União, dos Estados, do Distrito Federal e dos Municípios. Nesse contexto, os investimentos com tecnologia e inovação, embora venham apresentando tendência de crescimento, giram em torno de apenas 2,7\% do montante total do Judiciário (CNJ, 2017, p. 37) e, mesmo que a tramitação de processos judiciais por meio eletrônico tenha experimentado um expressivo crescimento, o número de tribunais que utilizam essa prática ainda é pequeno ${ }^{4}$. 
Os avanços ocorridos em Tecnologia da Informação (TI) não têm sido capazes de superar os gargalos existentes, como a demora na fase de execução, os baixos índices de conciliação ${ }^{5}$ e o constante congestionamento processual. E isso porque a mera existência de um banco de dados que permite a distribuição de informações às partes interessadas, por meio da internet, sobre o andamento de processos e o conteúdo de decisões judiciais, não é capaz, por si só, de incrementar de maneira significativa os índices de desempenho e produtividade.

Recentemente, o Supremo Tribunal Federal, em parceria com a Universidade de Brasília (UnB), passou a desenvolver o projeto denominado Victor ${ }^{6}$, em homenagem ao ex-Ministro Victor Nunes Leal ${ }^{7}$. 0 projeto envolve o que se chama de aprendizado de máquina (AM) e se utiliza, portanto, da aprendizagem computacional em IA.

A nova ferramenta que está sendo desenvolvida tem a finalidade de realizar o juízo acerca da repercussão geral no STF, avaliando a totalidade dos recursos extraordinários e agravos em recursos extraordinários que chegam à Corte, e investigar se cumprem o requisito determinado pelo art. 102, § 3oㅡ. da Constituição Federal, ou seja, se se vinculam a algum tema de repercussão geral. Nesse sentido, o projeto do STF pode vir a se constituir em poderosa ferramenta de utilização de IA que afetará positivamente o desenvolvimento do controle de constitucionalidade difuso realizado pela Corte.

A questão que se coloca é: o que se pode esperar da aplicação da IA no Poder Judiciário? Para além do armazenamento de bancos de dados, é possível considerar que o emprego de IA se constitui em ferramenta capaz de trazer uma nova dinâmica aos serviços judiciais? Como resposta, apresenta-se, neste artigo, estudo de caso relacionado ao desenvolvimento de iniciativa pioneira de aplicação de IA no âmbito do STF. A partir da descrição da execução inicial do Projeto Victor e à luz de referenciais teóricos, pode-se compreender a experiência e, inclusive, analisar como podem ser aprimorados projetos semelhantes de governança e tecnologia. 0 objetivo principal do presente artigo é, portanto, evidenciar, com base nas experiências iniciais do projeto, perspectivas de aplicação de IA ao Direito. 


\section{INOVAÇÃO E DIREITO}

Como observa Ray Kurzweil, (2015, p. 11), o processo evolutivo da tecnologia proporcionou "uma vasta expansão da nossa base de conhecimentos, facilitando muitos vínculos entre uma área de conhecimentos e outra". A inteligência artificial está inteiramente à nossa volta, de tal modo que "quase todo produto que tocamos foi desenhado originalmente por uma colaboração entre inteligências humanas e artificiais" (KURZWEIL, 2015, p. 151). A expansão das novas tecnologias permitiu sua apropriação por diferentes setores profissionais e de mercado, mas que não foi ainda suficientemente experimentada no Direito.

É preciso trazer também para o mundo jurídico as ferramentas tecnológico-algorítmicas que, de há muito, são de uso comum em outras áreas do conhecimento. 0 campo para que o Direito seja impactado por essas novas tecnologias é bastante amplo e promissor. Seu uso oferece oportunidades para a racionalização do trabalho desenvolvido pelos operadores do Direito - em particular os juízes e tribunais -, de maneira a permitir a execução de tarefas e a operação de sistemas com uma precisão que, frente ao exacerbado volume de processos existentes, é hoje impraticável.

As inovações tecnológicas têm o potencial de afetar de modo determinante as análises de dados, a fim de que se levantem informações e combinações de sentenças e dados envolvendo variados casos, as quais não poderiam ser adequadamente confrontadas utilizando-se os métodos tradicionais de pesquisa jurisprudencial (BAKER, 2018). 0 manejo, o controle e a categorização de processos judiciais poderão se dar de forma mais racional, permitindo uma análise de dados qualificada e abrangente, assim como o reconhecimento de padrões, o cruzamento de informações e a geração de insights oriundos de diferentes perspectivas e contextos.

A detecção de correlações e a criação de conexões entre diferentes processos e casos têm o potencial de permitir um entendimento mais profundo dos dados jurisprudenciais, da legislação e da doutrina levantada, oferecendo condições para a compreensão de como se deram os julgamentos passados, e em particular as razões que embasaram as 
decisões. Em vez de um mero painel de informações, o resultado da análise será capaz de apresentar um modelo estatístico no qual poderão ser feitas análises mais acuradas e preditivas.

Como acentuam Russel e Norvig, (1995, p. 4), a inteligência artificial é um campo genuinamente universal, abrangendo uma grande variedade de subcampos, que vão "desde áreas de uso geral, como a percepção e o raciocínio lógico, até tarefas mais específicas, como jogar xadrez, demonstrar teoremas matemáticos, escrever poesia e diagnosticar doenças". Na medida em que sintetiza e automatiza tarefas intelectuais, ela é potencialmente relevante para qualquer área da atividade intelectual humana, aí incluído o Direito.

No âmbito jurídico, as novas formas de tecnologia têm sido aplicadas basicamente na advocacia privada, de que é exemplo o aplicativo Ross, ligado ao sistema Watson da IBM, sendo ainda bastante incipiente sua utilização no Poder Judiciário ${ }^{8}$. Outra experiência bem-sucedida, nesse terreno, é o sistema Dra. Luzia, plataforma de inteligência artificial aplicada a execuções fiscais, voltada basicamente a Procuradorias Jurídicas estaduais, por meio da qual se faz peticionamento automático a partir de machine learning, assim como gestão de processos jurídicos e acompanhamento de resultados (FERNANDES et al., 2018).

Importante considerar que, se as técnicas de IA são capazes de indicar decisões ou reconhecer textos, falas ou imagens visuais, elas não prescindem do fator humano, necessário para avaliar as respostas, a evolução e a própria disciplina da computação cognitiva. 0 ser humano é quem controla a entrada de dados (inputs) e fornece comentários sobre a precisão dos resultados que as máquinas apresentam. Em outras palavras, o ser humano gerencia a informação, produto que se tornou valioso diante das tecnologias disruptivas (HILDEBRANDT, 2018). Além disso, o controle e a regulação jurídica das ferramentas tecnológicas são sempre necessários para garantir sua utilização de forma ética e responsável, de modo a preservar a autonomia dos indivíduos e os direitos constitucionalmente garantidos como, por exemplo, a privacidade dos dados (SILVEIRA, 2017).

Como assinala Alexander Galloway, professor da Universidade de Nova York, é errado considerar que a internet é uma força que elimina 
regulação, hierarquia, organização, controle etc. "Redes distribuídas nunca estão 'fora de controle' - este é o pior tipo de ilusão ideológica”, diz Galloway, (2009), para afirmar que basta considerar os protocolos (o conjunto de regras e convenções padronizadas que devem ser obedecidas a fim de permitir a troca de informações entre computadores ligados em rede) para se constatar que as regulamentações existem e são essenciais para o bom funcionamento das redes digitais. Nesse sentido, a questão fundamental não é se há ou não controle, mas sim perguntar qual é a qualidade desse controle e de onde ele vem, de maneira a assegurar a participação da sociedade na regulamentação que se faz necessária para a própria garantia da liberdade de expressão e de comunicação.

A normatização do uso da inteligência artificial é algo que não deve ser postergado, embora, como observa Atheniense, (2018, p. 158), tenhamos que "admitir que sequer atingimos de fato experiências maduras para apurar com isenção os riscos, benefícios e limites de conformidade ética e legal dessa nova cultura digital". A elaboração de arcabouços legais e de regulação ética sobre a matéria faz-se urgente, pois são inegáveis, no mundo atual, os impactos sociais e culturais do desenvolvimento tecnológico centrado em dados.

\section{A EXPERIÊNCIA DO PROJETO VICTOR: LIÇÕES IMPORTANTES}

O projeto de "Pesquisa \& Desenvolvimento de aprendizado de máquina (machine learning ${ }^{9}$ ) sobre dados judiciais das repercussões gerais do Supremo Tribunal Federal", intitulado Victor, que o Supremo Tribunal Federal está desenvolvendo em convênio com a Universidade de Brasília, apesar de estar em sua fase inicial, já indica uma notável capacidade de gerar inovações. Trata-se de projeto que envolve a parceria entre três cursos da UnB: Direito, Engenharia de Software e Ciência da Computação. Como assinalado, o projeto tem por objeto a aplicação de métodos de aprendizado computacional de máquina com o objetivo de usar seus potenciais no reconhecimento de padrões nos processos jurídicos relativos a julgamentos de repercussão geral do STF. 
Mesmo contando com equipe especializada em Tecnologia da Informação, a Suprema Corte decidiu que a execução do projeto deveria ser feita por agentes externos sob sua fiscalização, a fim de não sobrecarregar os especialistas do Tribunal, bem como para unir esforços multidisciplinares em pesquisa, proporcionando importantes ganhos também para a comunidade acadêmica brasileira (TOLEDO, 2018).

Visando o desenvolvimento de um sistema composto de algoritmos de aprendizagem profunda de máquina que viabilize a automação de análises textuais desses processos, Victor prevê a criação de modelos de machine learning para análise dos recursos recebidos pelo STF quanto aos temas de repercussão geral mais recorrentes, de modo a integrar o parque de soluções do Tribunal.

O objetivo do projeto não é que o algoritmo tome a decisão final acerca da repercussão geral, mas sim que, com as máquinas "treinadas" para atuar em camadas de organização dos processos, os responsáveis pela análise dos recursos possam identificar os temas relacionados de forma mais clara e consistente (STF, 2018). Isso vai gerar, em consequência, mais qualidade e velocidade ao trabalho de avaliação judicial, com a redução das tarefas de classificação, organização e digitalização de processos.

0 desenvolvimento de tecnologia inovadora em termos de métodos de reconhecimento de padrões oriundos da área de inteligência artificial, em particular o aprendizado automático, tem trazido excelentes resultados em diferentes campos de aplicação, sendo de todo oportuno que seja utilizada, pela Corte máxima do país, em sistema tão sensível como o da repercussão geral.

O instituto da repercussão geral foi criado pela Emenda Constitucional n. 45/2004 (Reforma do Judiciário) e regulamentada inicialmente pela Lei n. 11.418/2006, levando-se em consideração o número massivo de processos idênticos e analisados em sequência que tramitam no STF. Visava evitar que milhares de casos análogos fossem julgados de forma diferenciada, ao tempo em que possibilitaria que as decisões da Corte sobre tais casos tivessem o chamado efeito multiplicador (LIMA; ANDRADE; OLIVEIRA, 2015). Considerando que a maior parte dos assuntos que chegam ao STF já passou pelo crivo do duplo grau de jurisdição, passouse a considerar que, se determinada questão não possuísse relevância 
social, política, econômica ou jurídica que transcendesse os interesses subjetivos da causa, inexistiria interesse público em discuti-lo. Com isso, se evitaria que a Corte fosse sobrecarregada por um número excessivo de demandas e se uniformizaria a interpretação constitucional.

A implantação do instituto contribuiu, nos anos iniciais, para que a distribuição de processos no STF diminuísse significativamente. 0 quadro atual, entretanto, segue carregado: mais de 100 mil processos por ano chegam ao STF, praticamente o mesmo número anterior a 2007, ano em que, com a alteração do Regimento Interno do STF, a repercussão geral foi inteiramente implantada. Em 2017, a Corte proferiu 126.530 decisões, mas recebeu 103.506 processos novos no mesmo período (BARROSO; REGO, 2017). Ainda que mudanças de diferentes aspectos precisem ser consideradas para o enfrentamento desse congestionamento, a implantação de modelos de machine learning e de análise de redes complexas servirá, certamente, para o aperfeiçoamento do sistema de repercussão geral e da própria jurisdição constitucional.

Após o estudo dos dados das repercussões gerais para estruturação e preparação para treinamento dos modelos de aprendizado de máquina supervisionados e não supervisionados, o projeto desenvolverá pesquisa dos possíveis algoritmos e estratégias de treinamento mais eficientes para o contexto estudado, englobando redes neurais artificiais profundas, para, em seguida, realizar a prototipação e treinamento dos algoritmos escolhidos, incluindo a sua avaliação. A etapa seguinte consiste na preparação da arquitetura de comunicação para classificação de processos em tempo real, juntamente com a interface de registro de possíveis erros nas respostas dos modelos e a implantação do módulo dos modelos de classificação de machine learning treinados (SILVA, 2018).

O uso de métodos de machine learning em contexto jurídico é experiência inovadora e configura tecnologia ainda pouco pesquisada, o que torna o projeto uma iniciativa pioneira e de importância fundamental para o Judiciário, por envolver esforços comuns de distintas áreas do conhecimento em prol da modernização e melhoria da eficiência da prestação jurisdicional.

E como tem sido essa experiência ímpar de aplicação da IA ao Direito? A prática de construção conjunta - com equipes multidisciplinares de 
alunos, sob a supervisão de docentes - de modelo de aplicação de IA ao Direito tem manifestado diversas e interessantes perspectivas. 0 desenvolvimento da fase inicial do Projeto Victor centra-se nos temas de maior incidência no STF (nos anos de 2016 a 2018, os dois últimos anteriores à pesquisa), que possibilitam a formação de banco de dados relevantes capazes de permitir a construção dos modelos de classificação de aprendizagem automática.

Nesse sentido, a formação do banco de dados é passo importante que apresenta, por si só, elementos fundamentais para a administração do Judiciário brasileiro, os quais, analisados pelo STF e pelo CNJ, podem possibilitar a compreensão: $a$ ) dos litigantes mais frequentes que chegam ao STF; $b$ ) dos temas de repercussão geral que têm maior volume de processos vinculados e, consequentemente, dos temas recentes que cumprem com maior eficácia os objetivos da repercussão geral; c) de quais questões constitucionais estão sofrendo maior judicialização; $d$ ) de eventuais casos excepcionais que são reiterados e similares (podendo formar precedentes), mas ainda não se enquadram em algum tema atualmente existente. Possibilita-se, dessa forma, o diagnóstico atual da repercussão geral, o que potencializa a melhoria no manejo desse importante instrumento.

Trabalhando com cerca de 14.000 processos, a equipe do projeto centrou-se, inicialmente, na tarefa de separação e classificação de peças aquelas mais importantes, segundo a equipe do STF, para a identificação dos temas de repercussão geral de maior incidência: acórdão, recurso extraordinário, agravo em recurso extraordinário, despacho de admissibilidade e sentença. Visando ao treinamento dos modelos de aprendizado de máquina, a equipe do Curso de Direito da UnB criou um conjunto confiável de dados, extraídos dos processos analisados, com a conversão de imagens em textos no processo digital, separação do começo e do fim dos documentos, com a identificação do conteúdo de cada peça jurídica, além das similaridades e das discrepâncias existentes entre elas (SILVA et al., 2018).

Mediante a utilização de diferentes modelos de aprendizado de máquina, foram alcançados elevados níveis de assertividade na separação de peças, o que faz com que a fase seguinte do projeto - a identificação 
e classificação dos temas de repercussão geral - apresente perspectivas promissoras de bons resultados, constatáveis quando se for relacionar um processo inteiro a um ou mais temas de repercussão geral (SILVA, 2018). Nesse sentido, o conhecimento acumulado na aplicação dos modelos de aprendizado de máquina na separação de peças facilitará sobremaneira a utilização de modelos que tornem dispensável a análise de processos inteiros para concluir sua relação com temas de repercussão geral.

Frente às causas idênticas que são submetidas em grande volume à Corte Constitucional, os precedentes judiciais são capazes de demonstrar que as situações cotidianas "judicializáveis" reiteram-se e, pelo princípio da isonomia, devem ser decididas de maneira uniforme (JUNQUILHO; JEVEAUX, 2016). Daí, aquilo que se repete no Judiciário e abarrota a jurisdição tem grande potencial para aplicação de IA, além de proporcionar que, a partir de um recorte dos dados coletados, armazenados e processados, a Corte tenha condições de se debruçar nos casos que são, de fato, extraordinários. Isso é, nos casos difíceis, que evidenciam o papel precípuo do STF de guarda da Constituição (PANUTTO, 2017).

Outro aspecto significativo na realização da pesquisa é o acompanhamento da forma como se realiza a análise do regime de repercussão geral no STF. A observação do modus operandi do processamento do controle de constitucionalidade difuso também proporciona a melhoria na precisão (acurácia) da produção de qualquer sistema que se proponha a realizar aprendizagem de máquina. Isso porque a aproximação e observação reiterada de como o trabalho atualmente é realizado é fator que proporciona a maior eficácia possível na construção do projeto.

0 procedimento de concepção da pesquisa é um dos resultados relevantes que o Projeto Victor propicia. A metodologia empregada e os passos que levarão à sua construção final, pelo seu ineditismo, representam modelo inovador, ainda que sujeito a gradativo aperfeiçoamento. Tornase, portanto, referência na aplicação de IA ao mundo jurídico a nível nacional e mesmo em escala mundial.

O projeto, tal como concebido, pode inovar de forma significativa os procedimentos de análise da repercussão geral no STF, com a entrega de 
instrumentos tecnológicos que permitam à Corte não apenas a separação de peças jurídicas importantes nos processos para a avaliação do tema tratado em cada caso, mas que possibilitem, também, a agilização dos trâmites e das técnicas que envolvem a verificação dos requisitos constitucionais que permeiam o controle de constitucionalidade difuso. Como anunciado pela ex-presidente do STF, ministra Cármen Lúcia ${ }^{10}$, os testes realizados até agora, iniciados com 27 temas mais recorrentes (que representam 60\% do total de temas regularmente identificados), permitiu um nível de precisão na triagem que alcança, por ora, 84\%, com boas perspectivas de aprimoramento.

\section{PERSPECTIVAS DO USO DE IA NO PODER JUDICIÁRIO: 0 QUE PODEMOS APRENDER COM O PROJETO VICTOR}

A experiência do Projeto Victor traz luz às perspectivas que a IA e a tecnologia podem gerar, quando aplicadas ao Poder Judiciário. Dentre os prognósticos do que pode ocorrer, tendo em conta as pesquisas que estão em curso, é de se ressaltar: a) a redução no tempo de tramitação de processos, em virtude da automação de procedimentos técnicos, o que fortalece, inclusive, a concretização do princípio da eficiência administrativa (TOLEDO, 2018); b) o desenvolvimento de tecnologias e pesquisas genuinamente brasileiras, que levem em conta as particularidades do nosso congestionado sistema judicial; c) o incremento da agilidade e eficácia das ferramentas de consulta processual e jurisprudencial, o que gera também economia de tempo, precisão e coerência institucional (BAKER, 2018); d) o tratamento isonômico das questões apresentadas ao Judiciário, que torna mais eficazes os princípios do contraditório, da ampla defesa e do livre acesso à justiça.

O Projeto Victor propôs-se a ser pioneiro na aplicação de IA ao Judiciário com a finalidade de, a partir do STF, disponibilizá-la para os diversos tribunais de segundo grau espalhados pelo país e para inspirar projetos de idêntico teor. Logo após o anúncio do projeto, vieram à tona manifestações de outros tribunais ${ }^{11}$ na defesa do uso da inteligência artificial, em um movimento que favorece não apenas os advogados e 
demais operadores do Direito como também, de modo particular, os jurisdicionados, com a redução do tempo de duração dos processos e a viabilização de meios da Constituição Federal que garantam a celeridade de sua tramitação (art. 5ํㅜ, LXXVIII).

Há receios no desenvolvimento de projetos que apliquem IA ao Judiciário? Não se pode negar que sim. Dentre eles, pode-se apontar: $a$ ) os vieses cognitivos que podem ocorrer com a programação (O'NEIL, $2016)^{12}$; b) a necessidade de melhor regulamentação na contratação das empresas, eis que a Lei no 8.666/1993 tem se mostrado inadequada quando se trata de investimentos públicos em inovação (TOLEDO, 2018); c) o máximo cuidado com o uso dos dados (SILVEIRA, 2017). Todos esses riscos devem ser analisados e avaliados com cautela sempre que se busca realizar qualquer projeto público em inovação responsável, de maneira a se prezar, sempre, pela proteção de sua segurança e eficiência.

Mas existe, por fim, o temido risco de substituição do homem pela máquina? Essa predição, para Jamie J. Baker, (2018), ainda se mostra distante, pois a capacidade da computação não está pronta para substituir profissões altamente qualificadas. "Especialistas geralmente concordam que o maior potencial de melhoria para o futuro imediato ainda está em tarefas rotineiras e repetitivas", diz Baker (2018, p. 20), e, na medida em que a pesquisa jurídica não é rotineira nem repetitiva, ela ainda está longe, no curto prazo, de ser inteiramente automatizada. Para o autor, a pesquisa jurídica, por ser altamente sofisticada, possui uma "habilidade que requer um nível de pensamento mais adequado ao cérebro humano" (BAKER, 2018, p. 20).

\section{CONSIDERAÇÕES FINAIS}

A inteligência artificial poderá, em relativo espaço de tempo, representar um instrumento de suporte e apoio às decisões judiciais, permitindo maior eficácia na transmissão das informações, expondo analogias e contradições que seriam difíceis de identificar se os dados fossem analisados de forma manual ou separadamente. Sua adoção facilitará sobremaneira a interação entre o juiz que analisa o contexto 
do processo e os dados apresentados pelo instrumental tecnológico. Será mais fluido e fidedigno o trabalho de selecionar a legislação e a jurisprudência aplicável, auxiliando sobremaneira o processo de fundamentação da decisão a ser tomada.

As tecnologias de computação cognitiva são capazes de selecionar e separar milhões de documentos de texto em frações de segundos, reduzindo os custos operacionais envolvidos. Mais que sistemas de pesquisa focados no armazenamento e processamento de dados, essas tecnologias auxiliarão o trabalho de investigação das leis e dos precedentes judiciais, classificando as informações de interesse e indicando soluções mais adequadas, bem como melhores condições ao juiz para, com base em elementos lógicos, decidir ou despachar. No mesmo sentido, permitirão a aceleração das diversas fases do trâmite processual e a superação de deficiências relacionadas ao trabalho manual e à carência de pessoal e de recursos materiais que caracterizam a Administração Pública, como um todo, e o Poder Judiciário em particular.

Nesse cenário, é de se perguntar em que medida a experiência do Projeto Victor poderá agregar valor ao trabalho desenvolvido pela Corte Suprema do país, contribuindo para as futuras e inevitáveis aplicações da IA ao Direito. Uma pesquisa como essa, inovadora e multidisciplinar, para além dos resultados específicos que auxiliem o trabalho da jurisdição constitucional realizado pelo STF, abre também caminhos para o desenvolvimento de outros sistemas e aplicações de IA nos mais diversos níveis dos Poderes, tanto em âmbito federal como estadual e municipal. o know-how alcançado pela equipe do projeto sobre o procedimento de elaboração, suas fases e êxitos, contribuirá para aumentar a eficiência e apontar os melhores caminhos para projetos futuros que, muito em breve, irão se disseminar na esfera judicial, com a adoção e o desenvolvimento das tecnologias de IA.

Para o STF, em particular, a adoção dos modelos de aprendizado de máquina que o Projeto Victor irá oferecer permitirá que se conclua, de forma segura, a relação dos processos analisados com temas de repercussão geral, gerando agilidade e economia na classificação de peças e temas. Confrontada com bons resultados, a Administração Pública como um todo poderá incrementar o uso dessas tecnologias, ampliando a 
oferta de plataformas digitais e aplicativos que impactarão positivamente a percepção do usuário sobre o valor dos serviços públicos prestados. Auxiliando a qualidade e a segurança dos dados e informações, a indexação de conteúdos, a prevenção de erros, a economia de tempo no trabalho e fornecendo mais ferramentas para o processo de tomada de decisões, a utilização de IA prenuncia um grande potencial transformador para o Direito, gerando benefícios que o Projeto Victor, de forma pioneira, ajudará a mensurar. Ela oferece condições para que os tribunais, e o STF em particular, resolvam seu déficit de produtividade e reforcem a autoridade de suas decisões, e, por que não dizer, o prestígio mesmo do Direito.

\section{NOTAS}

1 Entre as ideias abordadas no romance de Huxley (1969) que vieram, depois, a se tornar realidade estão a fertilização in vitro, a manipulação genética e a programação neurolinguística, entre outras.

2 Sobre os temores de que o homem perca o controle dos avanços da IA e da biotecnologia, ver Harari (2016).

3 A aplicação de IA vai desde a indústria, com a utilização de peças robóticas (por exemplo, no setor automobilístico) até os serviços de entretenimento, passando pelos bancos, lojas de varejo na internet e jornalismo. A IA também é amplamente utilizada nos jogos de vídeo e aplicativos de música, assim como no setor de saúde, auxiliando nos diagnósticos e na indicação de tratamentos.

4 No âmbito da Justiça Estadual, por exemplo, dos 27 tribunais, somente quatro têm todos os processos de $1^{\circ}$ e $2^{\circ}$ grau ingressando de forma eletrônica. De igual maneira, na Justiça Eleitoral apenas cinco tribunais tiveram processos ingressados eletronicamente no ano de 2016 (Relatório Justiça em Números, p. 100).

5 Apenas 11,9\% das sentenças e decisões proferidas no Poder Judiciário em 2016 foram homologatórias de acordo, tomando por parâmetro o total de sentenças e decisões terminativas proferidas. Cf. Relatório Justiça em Números 2017, p. 125.

6 "Inteligência artificial vai agilizar a tramitação de processos no STF". Disponível em: <http://www. stf.jus.br/portal/cms/verNoticiaDetalhe.asp?idConteudo=380038>. Acesso em: 13 jul. 2018.

7 Ministro do STF de 1960 a 1969, o autor de "Coronelismo, Enxada e Voto" foi o principal responsável pela sistematização da jurisprudência do STF em súmulas.

8 A tecnologia Ross foi criada para pesquisa de conteúdo jurídico on-demand. Utilizando processamento de linguagem natural (PLN, no inglês Natural Language Process - NLP), proporciona ao usuário respostas às mais diversas dúvidas jurídicas. A tecnologia pode ser acessada no site: https://rossintelligence.com/. Acesso em: 08 nov.2018.

9 Giuffrida, Lederer e Vermeys dão uma boa definição sobre aprendizado de máquina - machine learning (2018, p. 753, tradução nossa): “0 aprendizado de máquina pode ser resumido como a capacidade de um computador de modificar sua programação para dar conta de novos dados e modificar suas operações de acordo com eles. Ele usa computadores para executar modelos preditivos que aprendem com os dados existentes para prever futuros comportamentos, resultados e tendências. "O aprendizado de máquina, portanto, depende de dados. Quanto mais dados puder acessar, melhor poderá 'aprender'”.

10 "Ministra Cármen Lúcia anuncia início de funcionamento do Projeto Victor, de inteligência artificial" - Notícias STF. Disponível em: http://www.stf.jus.br/portal/cms/verNoticiaDetalhe.asp? idConteudo=388443. Acesso em: 31 ago.2018. 
11 O novo presidente doSTJ, ministro João Otávio de Noronha, por exemplo, em entrevista concedida em 06/06/2018, enfatizou a necessidade de uso da inteligência artificial para redução do tempo de tramitação dos processos. Disponível em: <http://www.stj.jus.br/sites/STJ/default/pt_BR/ Comunica\%C3\%A7\%C3\%A3o/noticias/Not\%C3\%ADcias/Futuro-presidente-aposta-na-tecnologia-para-acelerar-presta\%C3\%A7\%C3\%A3o-jurisdicional>. Acesso em: 21 ago. 2018.

12 Cathy O’Neil (2016) denuncia a formação de vieses que podem ocorrer de forma intencional ou não intencional na programação. Isso porque, quando os dados utilizados para a elaboração da tecnologia são processados "friamente" por matemáticos e cientistas da computação - sem o devido tratamento que vise a eliminar preconceitos e atribuir transparência aos algoritmos pode-se chegar a medidas de inovação que perpetuam a opressão social. Isso é, que têm potencial para se tornar verdadeiras "armas de destruição matemática” (expressão que dá título ao livro da autora).

\section{REFERÊNCIAS}

ATHENIENSE, Alexandre Rodrigues. As premissas para alavancar os projetos de inteligência artificial na Justiça brasileira. In: FERNANDES, Ricardo Vieira de Carvalho; CARVALHO, Angelo Gamba Prata de (Coord.). Tecnologia jurídica \& direito digital: II Congresso Internacional de Direito, Governo e Tecnologia. Belo Horizonte: Fórum, 2018.

BARROSO, Luís Roberto. Vinte anos da Constituição de 1988 - A reconstrução democrática do Brasil, Revista de Informação Legislativa, n. 179, jul./set. 2008.

; REGO, Frederico Montedonio. Como salvar o sistema de repercussão geral: transparência, eficiência e realismo na escolha do que o Supremo Tribunal Federal vai julgar. In: Revista Brasileira de Políticas Públicas, v. 7, no 3, 2017.

BAKER, Jamie J. 2018: A Legal Research Odyssey: Artificial Intelligence as Disruptor. Law Library Journal, Vol. 110:1 [2018-1]. Disponível em: <http://web.b-ebscohost-com.ez54.periodicos.capes.gov.br/ehost/detail/ detail?vid=0\&sid=b2b070db-c438-4e40-888e-9111f 72d51cd\%40pdc-v-sess mgr02\&bdata=Jmxhbmc9cHQtYnImc210ZT1laG9zdC1saXZl\#AN=130412930 $\& d b=l i h>$. Acesso em: 20 out. 2018.

CONSELHO NACIONAL DE JUSTIÇA. Relatório Justiça em Números 2017: ano-base 2016/Conselho Nacional de Justiça - Brasília: CNJ, 2017. Disponível em: < 
http://www.cnj.jus.br/files/conteudo/arquivo/2017/12/

b60a659e5d5cb79337945c1dd137496c.pdf>. Acesso em: 12 jul. 2018.

FERNANDES, Ricardo Vieira de Carvalho; MENDES, Danilo Barros;

FERREIRA, Hugo Honda; GUEDES, André Bernardes Soares. Inteligência Artificial (IA) aplicada ao direito: como construímos a Dra. Luzia, a primeira plataforma do Brasil com machine learning utilizado sobre decisões judiciais. In: FERNANDES, Ricardo Vieira de Carvalho; COSTA, Henrique Araújo; CARVALHO, Angelo Gamba Prata de (Coord.), Tecnologia jurídica e direito digital: I Congresso Internacional de Direito e Tecnologia. Belo Horizonte: Fórum, 2018.

GALLOWAY, Alexander. Rede é regulação e nada mais - Entrevista com Alexander Galloway. Cultura Digital, 2009. Disponível em: <http:// culturadigital.br/blog/2009/10/30/entrevista-com-alexander-galloway/>. Acesso em: 10 ago. 2018.

GIUFFRIDA, Iria; LEDERER, Fredric; VERMEYS, Nicolas. A legal perspective on the trials and tribulations of ai: how artificial intelligence, the internet of things, smart contracts, and other technologies will affect the law. Case Western Reserve Law Review, v. 68, n. 3, p. 747-782, 2018.

HARARI, Yuval Noah. Homo Deus: uma breve história do amanhã. Tradução de Paulo Geiger. São Paulo: Companhia das Letras, 2016.

HILDEBRANDT, Mireille. Law as computation in the era of artificial legal intelligence. Speaking law to the power of statistics. University of Toronto Law Journal, Volume 68, Supplement 1, p. 12-36, 2018.

HUXLEY, Aldous. Admirável mundo novo. 11. ed. Tradução de Felisberto Albuquerque. Rio de Janeiro: Cia. Brasileira de Divulgação do Livro, 1969.

JUNQUILHO, Tainá Aguiar; JEVEAUX, Geovany. C. "Tupi, or not tupi”: a necessária e definitiva adaptação da teoria dos precedentes ao Brasil. Revista da Faculdade Mineira de Direito - PUC Minas. V. 19, n. 38, p. 86-101, 2016.

KURZWEIL, Ray. Como criar uma mente: os segredos do pensamento humano. Tradução de Marcello Borges. São Paulo: Aleph, 2015. 
LIMA, Flávia Danielle Santiago; ANDRADE, Louise Dantas de; Oliveira, TASSIANA, Moura de. As (in)alterações do novo código de processo civil na repercussão geral: apontamentos sobre a atuação do STF. Revista CEJ, Brasília, Ano XIX, n. 67, p. 78-84, set./dez. 2015.

O'NEIL, Cathy. Weapons of math destruction: how big data increases inequality and threatens democracy. Nova York: Crown Publishers, 2016.

PANUTTO, Petter. A plena deliberação interna do supremo tribunal federal para a efetiva criação dos precedentes Judiciais vinculantes estabelecidos pelo novo código de processo civil. Revista de Direitos e Garantias Fundamentais, Vitória, v. 18, n. 2, p. 205-226, mai./ago. 2017.

RUSSELL, Stuart Jonathan; NORVIG, Peter. Artificial intelligence: a modern approach. New Jersey: Prentice Hall, 1995.

SILVA, Nilton Correia da. Notas iniciais sobre a evolução dos algoritmos do Victor: o primeiro projeto em inteligência artificial em supremas cortes do mundo. In: FERNANDES, Ricardo Vieira de Carvalho; CARVALHO, Angelo Gamba Prata de (Coord.). Tecnologia jurídica \& direito digital: II Congresso Internacional de Direito, Governo e Tecnologia - 2018. Belo Horizonte: Fórum, 2018.

et al. Document type classification for Brazil's Supreme Court using a Convolutional Neural Network. The tenth international conference on forensic computer science and cyber law - ICoFCS 2018. p. 7-11, 2018.

SILVEIRA, Sergio Amadeu de. Tudo sobre tod@s: Redes digitais, privacidade e venda de dados pessoais. São Paulo: Edições SESC, 2017.

SUPREMO TRIBUNAL FEDERAL - Notícias STF. "Inteligência artificial vai agilizar a tramitação de processos no STF". 30 maio 2018.

Disponível em: <http://www.stf.jus.br/portal/cms/verNoticiaDetalhe. asp?idConteudo=380038> . Acesso em: 10 ago. 2018. 
Notícias STF. "Ministra Cármen Lúcia anuncia início de funcionamento do Projeto Victor, de inteligência artificial”. 30 ago. 2018. Disponível em: <http://www.stf.jus.br/portal/cms/verNoticiaDetalhe. asp?idConteudo=388443>. Acesso em: 31 ago. 2018.

TOLEDO, Eduardo S. Projetos de inovação tecnológica na Administração Pública. In: FERNANDES, Ricardo Vieira de Carvalho; CARVALHO, Angelo Gamba Prata de (Coord.). Tecnologia jurídica \& direito digital: II Congresso Internacional de Direito, Governo e Tecnologia - 2018. Belo Horizonte: Fórum, 2018.

Recebido em: 22-11-2018

Aprovado em: 18-12-2018

\section{Mamede Said Maia Filho}

Doutor em Direito pela Universidade de Brasília, professor adjunto e atual Direitor da Faculdade de Direito da Universidade de Brasília. E-mail: mamedesaid@gmail.com

\section{Tainá Aguiar Junquilho}

Doutoranda em Direito (UnB). Mestre em Direito (UFES). Pós-Graduada em Fazenda Pública em Juízo (FDV). Professora. Advogada. Programa de PósGraduação em Direito. E-mail: taina.aguiarj@gmail.com

Faculdade de Direito - Universidade de Brasília. Campus Universitário Darcy Ribeiro, Brasília/DF, CEP 70919-970. 
